\title{
LA INTERPRETACIÓN CONFORME CON LA CONSTITUCIÓN EN LOS LÍMITES DEL MANDATO DE CERTEZA
}

\section{THE CONSTITUTIONAL AVOIDANCE CANON AND VOID-FOR- VAGUENESS DOCTRINE}

\author{
José Ángel FernándeZ*
}

\begin{abstract}
RESUMEN: La interpretación conforme con la Constitución constituye un mecanismo de control de constitucionalidad adecuado para solventar problemas de certeza en la descripción de normas penales. No obstante, si la disposición normativa no contiene un mínimo de precisión y claridad, el Tribunal Constitucional debe abstenerse de realizar una interpretación conforme con la Constitución y, en su lugar, debe declarar su inconstitucionalidad.
\end{abstract}

Palabras clave: Interpretación conforme con la Constitución, mandato de certeza, valor normativo de la jurisprudencia.

ABSTRACT: Interpretation according to Constitution (constitutional avoidance canon) is appropriate in void-for-vagueness cases. However, whether the statute itself, as constituted, does not satisfied the basic requirements of absence of vagueness, Constitutional Court must abstain from using constitutional avoid canon, but instead must declare it unconstitutional.

Key words: Constitutional avoidance canon, void-for-vagueness doctrine, precedents in law

\section{INTRODUCCIÓN}

Los tribunales constitucionales a la hora de controlar la constitucionalidad de una ley penal pueden acudir a la denominada interpretación conforme con la Constitución (en lo sucesivo ICC). Este tipo de interpretación, si bien ha sido objeto de un rico debate doctrinal por parte de la dogmática constitucional y de la teoría del derecho, también presenta algunas particularidades cuando esta recae en una norma penal. Este artículo pretende dar cuenta de aquellas que se producen en el contexto del principio de legalidad penal y, en especial, respecto del mandato de certeza.

El estudio se sistematizará en seis grandes apartados. El primero realizará una somera referencia a los principales contextos en los que se plantean problemas de certeza. El segundo dará cuenta del conflicto interno entre los diferentes fines o fundamentos del mandato de certeza y sus implicancias en una eventual ICC. El tercero, señalará algunas reglas interpretativas a la hora de acudir a la ICC como mecanismo de determinación de las normas penales. El cuarto abordará las limitaciones contempladas en los mandatos de lex certa y

\footnotetext{
* Doctor en Derecho, Universidad Europea de Madrid. Profesor de Derecho penal y Teoría criminológica de la Facultad de Ciencias Jurídicas y Sociales de la Universidad Austral de Chile. Dirección postal: Av. Elena Haverbeck, s/n, Campus Isla Teja, Valdivia. Correo electrónico: josefernadez@uach.cl.
} 
lex stricta. El quinto hará referencia a la jurisprudencia como complemento en la determinación de las normas penales y sus implicancias en la ICC. Y el sexto realizará una somera referencia a la jurisprudencia del TC chileno.

No obstante, antes de señalar estas peculiaridades, resulta necesario realizar una pequeña aproximación conceptual, además de tomar partido sobre algunas de las cuestiones problemáticas que presenta esta forma de control de constitucionalidad ${ }^{1}$.

Podemos definir a la ICC como una interpretación de una disposición infraconstitucional de acuerdo con las normas constitucionales, que tiene como finalidad evitar una sentencia estimativa de inconstitucionalidad. La ICC puede consistir en señalar la única o únicas posibles interpretaciones de la norma infraconstitucional (dimensión positiva) y/o expulsar una determinada interpretación por considerarla contraria a la Constitución (dimensión negativa).

Estamos ante una forma de creación o cambio normativo sin modificación de texto, y la característica que le otorga autonomía conceptual reside en el establecimiento de "condiciones interpretativas de constitucionalidad": el precepto resulta constitucional si la norma se interpreta de cualquier manera, salvo la establecida como inconstitucional por el TC (dimensión negativa) o no se interpreta de la manera establecida por este (dimensión positiva). De esa manera, a partir de una determinada compresión de la Constitución, se realiza una interpretación correctora de la norma infraconstitucional que puede ser extensiva, si amplía los supuestos de hechos subsumibles, o restrictiva si, por el contrario, los reduce.

En este sentido, cuando el TC realiza una ICC, en especial en su faceta positiva, puede comprender algunas de estas dos formas: los pronunciamientos meramente declarativos, en los que el TC solo reproduce los contenidos normativos que ya se encontraban presentes en la praxis jurisprudencial ordinaria; y los pronunciamientos interpretativos auténticos, en los que el TC introduce ex novo elementos que condicionan la comprensión del precepto legal más allá de la interpretación asentada en otras instancias jurisdiccionales.

Debe recalcarse que la ICC se encuentra afectada o limitada de manera expresa o latente por razonamientos de tipo institucional, que inciden a la hora de elegir esta forma de control de constitucionalidad y su contenido. Dentro de esta dimensión institucional, destacan las relaciones y tensiones con los poderes legislativo y/o judicial, que se articulan en una serie de principios (institucionales) como los de presunción de constitucionalidad de la ley, deferencia hacia el legislador (racional), conservación de las normas, reserva de interpretación de legalidad ordinaria, etc., que podemos aglutinar bajo el principio de corrección funcional. En cuanto al legislador, si bien, la ICC constituye una de las manifestaciones del citado principio, también su aplicación puede llevar al TC a convertirse en un órgano colegislativo, ya que una ICC puede ampliar o reducir sustancialmente el contenido normativo de una disposición infraconstitucional. Respecto del Poder Judicial, también genera tensiones con la función de unificación de jurisprudencia atribuida a los tribunales superiores de justicia ${ }^{2}$.

\footnotetext{
1 Las siguientes líneas toman como referencia: FERNÁNDEZ (2016) pp. 153-148.

2 Un caso paradigmático de esta tensión lo encontramos en el derecho italiano que se caracterizó por una confrontación entre Corte Constitucional y la Corte de Casación. En la actualidad, las relaciones entre la Corte
} 
Relacionado con la anterior consideración, entendemos que no existe una diferencia estructural entre la ICC realizada por los tribunales constitucionales y la interpretación orientada hacia la Constitución realizada por los tribunales ordinarios, sino una de tipo institucional: la conveniencia de que determinadas interpretaciones conforme a la Constitución las realice el TC y, por el contrario, otras recaigan en los tribunales ordinarios de justicia. Los tribunales constitucionales, en este sentido, deberían centrarse en declarar aquellas interpretaciones que resultan claramente contrarias a la Constitución, ya que, en la determinación de la mejor interpretación posible de acuerdo a la Constitución corresponde a los tribunales ordinarios (superiores).

\section{CONTEXTOS DE INCERTEZA O DE EXCESIVA DETERMINACIÓN EN EL DERECHO PENAL}

Una disposición normativa penal puede plantear tanto un problema de certeza o de excesiva determinación que suelen tener como causa dos tipos de situaciones. La primera cuando ha existido un defecto en la descripción de la noma penal y, la segunda, cuando la indeterminación de la norma penal refleja un conflicto entre derechos fundamentales o entre un derecho fundamental y la protección de un bien jurídico (constitucional). En este último caso, el legislador consciente o no considera que la mejor manera de abordar este conflicto entre normas constitucionales es que los tribunales, incluido el TC, lo resuelva precisando el significado de las disposiciones jurídicas. Así, por ejemplo, si redactáramos de manera precisa las condiciones de aplicación del delito de calumnia, obtendríamos unas altas cotas de certeza, pero se limitaría en exceso la entrada de otros principios en conflicto, como el de libertad de expresión. Debe tenerse presente que estos dos contextos en los que pueden aparecer problemas de certeza suelen concurrir de manera conjunta, ya que una situación de conflicto constitucional puede contribuir a que el legislador redacte de manera defectuosa la norma y viceversa.

\section{LA AUSENCIA DE CERTEZA O DE EXCESIVA DETERMINACIÓN COMO DEFECTO EN LA CONSTRUCCIÓN DE LAS NORMAS PENALES}

Los problemas de certeza, como consecuencia de un defecto en la descripción de una norma penal, pueden provenir de una incorrecta valoración legislativa o de una ausencia (injustificada) de esta ${ }^{3}$. En este último caso, encontramos el Art. $373 \mathrm{CP}$, donde el núcleo esencial de prohibición gira en torno al término de "buenas costumbres", quedando, por tanto, en manos de los jueces su determinación y condiciones de aplicación, es decir, el legislador ha omitido cualquier precisión a la hora de delimitar el término "buenas costumbres" ${ }^{4}$. En el primer caso, a pesar de que el legislador ha plasmado una decisión

Constitucional y la Corte Suprema han entrado en una fase de estabilización, presidida por la colaboración. Romboli (1999) pp. 28 y ss.

3 Por todos, Navarro (2010) p. 4.

4 Si bien, resulta, desde un punto de vista analítico, pertinente diferenciar entre ausencia de valoración e incorrecta valoración legislativa, cuando el legislador renuncia a valorar expresamente una determinada disposición 
valorativa en la descripción del tipo penal, esta no se traduce en una mayor precisión o concreción o, por el contrario, conlleva a una excesiva determinación de la norma penal. Así, puede concurrir un caso de sobreinclusión o infrainclusión que, a la vez, puede afectar a una norma favorece al reo (eximentes, penas o medidas alternativas a la prisión, etc.) o le perjudica (tipos penales, agravantes, etc.).

Respecto de los casos de sobreinclusión que perjudican al reo, un caso paradigmático consiste en la introducción de cláusulas abiertas en la descripción de tipos penales como, por ejemplo, la establecida en el Art. 3 de la Ley 20.000 que castiga como delito de tráfico de drogas "a quienes, por cualquier medio, induzcan, promuevan o faciliten el uso o consumo de tales sustancias". Aquí, la valoración del legislador no pretende concretar un determinado tipo penal, sino evitar dejar fuera conductas que, si bien no estuvieron presentes en el proceso legislativo, igualmente son merecedoras de pena ${ }^{5}$. Respecto de los casos de sobreinclusión de normas que favorecen al reo, tenemos el término "cualquier que sea el daño que se ocasione" en la denominada legítima defensa privilegiada del Art. 10. 6, inc. $2^{\circ} \mathrm{CP}$.

En cambio, en los casos de infrainclusión concurren cuando, debido a una excesiva determinación de la norma penal se ha dejado fuera de su ámbito de aplicación conductas merecedoras de sanción. Los casos de infrainclusión de normas que favorecen al reo suelen acontecer en el derecho penal de los poderosos (delitos medioambientales, económicos, etc.), es decir, se produce una excesiva determinación del tipo penal en detrimento de una adecuada protección del bien jurídico protegido. Un ejemplo de infrainclusión de normas que perjudican al reo puede ocurrir si en una futura despenalización parcial del aborto en Chile se describe con una excesiva precisión las causales que justifican o eximen la comisión de este. Véase que, en este caso, se produce de manera indirecta un caso de sobreinclusión que perjudica al reo, a saber, se amplía el ámbito de aplicación del delito de aborto.

En los sistemas penales de corte liberal, se entiende más grave el riesgo de que se tipifiquen conductas que no merecían ser castigadas, a que queden sin castigo conductas que merecían ser sancionadas. Así, se requiere una mayor precisión en la formulación de los tipos penales y las agravantes, además de prohibir la interpretación analógica en contra del reo. En cambio, para evitar que se castiguen conductas que no merecen sanción, el legislador suele formular en términos más vagos e imprecisos como, por ejemplo, las causas de exclusión de la culpabilidad (véase el miedo insuperable o la fuerza irresistible), además de permitirse la interpretación analógica a favor del reo ${ }^{6}$.

No obstante, la realidad legislativa nacional se aleja de este ideal liberal. En efecto, como una consecuencia más del modelo penal de seguridad ciudadana, los defectos de sobreinclusión en la descripción de normas que perjudican al reo se han tornado como un problema endémico en el derecho penal chileno. Ante esta situación, la ICC adquiere una mayor relevancia como mecanismo corrector en aquellos casos en que el legislador ha pretendido ampliar ilegítimamente el ámbito de aplicación de la norma penal.

normativa en muchas ocasiones su decisión no es neutral, sino que deja esta tarea a la clase dirigente (los jueces) para que interpreten, precisamente, de acuerdo con los valores que el legislador ha omitido en la descripción del texto normativo.

5 Ferreres (2002) p. 34; Navarro (2010) p. 4.

6 Ferreres (2002) pp. 35-37. 
2. La Ausencia de CERTEZa COMO REFLEJO de un CONFLicto CONSTITUCiONAL O DE LA APLICACIÓN DE OTROS PRINCIPIOS PENALES

La falta de certeza de una norma penal no solo puede tener como causa un defecto legislativo, sino que también puede reflejar un conflicto constitucional. Desde la perspectiva de los derechos y libertades fundamentales, la protección de estos tiene un impacto negativo sobre el mandato de certeza. El legislador penal debe satisfacer el principio de taxatividad, como un mandato de carácter formal, pero al mismo tiempo debe tener en cuenta en la mayor medida posible los derechos y libertades materiales reconocidos en la Constitución, que suelen estar configurados de manera imprecisa (libertad de expresión, igualdad, intimidad, honor, etc.) y, por tanto, su protección en el orden penal puede adolecer también de esta imprecisión.

Desde una aproximación dogmática de los principios y límites penales, también pueden generarse problemas de certeza. Así, por ejemplo, el carácter fragmentario del derecho penal establece que este solamente puede comprender los ataques más graves a los bienes jurídicos fundamentales en una determinada sociedad y contexto histórico determinado. Este mandato supone, sin duda, una garantía del ciudadano frente al poder punitivo del Estado, pero a la vez puede generar problemas de indeterminación. Si en la descripción de un delito medioambiental, se castigara "el vertido de sustancias químicas que puedan causar graves daños a los ecosistemas", este resultaría menos preciso que si solo se castigara el vertido de sustancias químicas, ya que excluye el término "grave daño al medio ambiente" que resulta vago e impreciso.

En todo caso, debe advertirse que la propia Constitución exige una mayor precisión en la protección de estos derechos e intereses constitucionales que la otorgada por ella misma, porque precisamente, es la ley su principal fuente de concreción ${ }^{7}$. Como manifiesta Ferreres Comella: "El legislador ordinario, pues, se encuentra ante un dilema. Cuanto más se abra la ley a los derechos constitucionales, en mayor grado asegurará la constitucionalidad material de esa ley, pero en mayor grado lesionará entonces al principio formal de taxatividad. Cuantas menos remisiones haga a los derechos constitucionales, en cambio, más preciso podrá ser, pero correrá entonces un mayor riesgo de lesionar alguno de estos derechos, Lo que la Constitución quiere es que el legislador penal sea preciso y, al mismo tiempo, acierte"

Podemos distinguir tres grupos de casos donde la protección de derechos fundamentales y bienes e intereses constitucionales interactúan con el mandato de certeza, conflictos que pueden ser resueltos mediante una ICC.

El primero concurre cuando la infracción penal consiste en la vulneración del ejercicio de un derecho o un interés constitucional que entra en conflicto con otras normas constitucionales que protegen otros derechos o bienes fundamentales. Así, por ejemplo, en los delitos contra la intimidad y el honor, si los derechos constitucionales que protegen estos delitos se interpretan de manera amplia, el ámbito de aplicación de esta figura penal tiende a expandirse de manera correlativa, con las consecuentes repercusiones en el manda-

\footnotetext{
7 Ferreres (2002) p. 64.

8 Ferreres (2002) p. 66.
} 
to de certeza. Como es bien conocido, este tipo de conflictos es resuelto a través del juicio constitucional de proporcionalidad. La utilización de la ICC no plantea especiales problemas, tanto en la determinación de si la norma infraconstitucional persigue un fin constitucionalmente ilegítimo, como en la delimitación del contenido normativo de esta conforme con una norma adscrita. Pero, sin embargo, debemos preguntarnos si la ICC resulta aplicable a la hora de adscribir prima facie la norma a una disposición de derecho fundamental. La determinación prima facie del conflicto constitucional constituye un proceso de interpretación en el que deben subsumirse las normas o posiciones de derecho fundamental en las disposiciones o textos estatuidos en la Constitución. Entonces podría afirmarse que, como consecuencia de los principios in dubio pro libertaten y de efectividad de los derechos fundamentales, los tribunales constitucionales realizan una suerte de ICC de las normas infraconstitucionales cuando realizan este tipo de adscripción normativa. Ahora bien, en estos casos los tribunales constitucionales no adscriben una condición de aplicación o lo suprime de manera definitiva sino, precisamente, prima facie. Por tanto, la ICC no resulta aplicable a la adscripción prima facie de una norma infraconstitucional ${ }^{9}$. Como conclusión, la ICC, por el contrario, deberá mitigar los problemas de certeza de la norma infraconstitucional a partir de sus relaciones con los denominados fines constitucionalmente ilegítimos, y con la posterior interpretación (subsunción) de las denominadas normas adscritas a una disposición iusfundamental.

El segundo consiste en la prohibición de calificar una conducta o agravarla como consecuencia del ejercicio legítimo de un derecho o libertad constitucional. Así, puede suceder que las causas de exclusión de la responsabilidad penal y las circunstancias atenuantes aplicables a estos delitos se encuentren redactadas de manera general e imprecisa y, por tanto, el ámbito de no punición tenderá a ampliarse. Como hemos mantenido con anterioridad, parte de la doctrina entiende que en estos casos las exigencias del mandato de certeza deben ser menos severas. Un mayor grado de imprecisión resulta asumible en las normas penales que excluyan la responsabilidad penal o la atenúen. El ejemplo paradigmático lo encontramos en la causa de justificación del ejercicio legítimo de un derecho. Véase aquí que el juez ordinario a la hora de subsumir el hecho en el derecho penal positivo, no solo deberá tener presente las condiciones de aplicación de la norma penal, sino otras normas extrapenales, incluso de rango constitucional.

Por último, la interacción entre los derechos y bienes fundamentales con el mandato de lex certa puede producirse en la determinación de la pena. En ocasiones, el legislador penal otorga al juez un importante margen de discrecionalidad para establecer la pena y/o su cuantía. Cabe distinguir entre una imprecisión de carácter cuantitativo, donde no queda claro a qué supuesto se refiere la sanción (por ejemplo, qué cargos se entienden incluidos dentro de la pena de inhabilitación); y otra de naturaleza cuantitativa debido a un marco penal demasiado amplio ${ }^{10}$. Desde una concepción de los fines de la pena como un derecho penal de alternativas, la mejor forma de salvaguardar los derechos y garantías constitucio-

\footnotetext{
9 Fernández (2016) pp. 180-181.

10 Ferreres (2002) p. 96.
} 
nales y, en especial, la libertad personal es otorgar un amplio margen de arbitrio judicial ${ }^{11}$, pero, la delimitación de las libertades afectadas por la pena y la forma de aplicar este arbitrio judicial deben ser precisas, claras y concretas por parte del legislador penal.

Como puede apreciarse, la ICC también puede ser un mecanismo útil para determinar tanto cualitativa como cuantitativamente la determinación de la pena.

\subsection{La protección de bienes jurídicos (constitucionales)}

En el control de constitucionalidad de las leyes penales suele presentarse un dilema entre el cumplimiento de los principios y garantías penales y la protección de bienes jurídicos. El legislador, por una parte, como consecuencia de su prerrogativa de determinar los lineamentos generales de la política criminal, disfruta de un amplio margen en la creación de normas penales; y por otra, la Constitución exige, especialmente en un ámbito tan invasivo en los derechos fundamentales, que se tenga en cuenta de forma suficiente sus límites y garantías ${ }^{12}$.

Efectivamente, una de las más poderosas razones que puede inducir a los tribunales constitucionales a adoptar una ICC, como alternativa a la inconstitucionalidad de la disposición legal impugnada, no se debe tanto a la protección de un derecho fundamental, sino a la necesidad de mantener la sanción penal sobre una determinada conducta pese al derecho fundamental. Así, frente al vacío normativo y la consiguiente desprotección penal, una decisión interpretativa permitiría adecuar la norma a las exigencias de la Constitución y proteger de manera adecuada el bien jurídico (constitucional) ${ }^{13}$.

Desde esta perspectiva, la declaración de invalidez de una norma penal por parte del TC produce un vacío jurídico que puede ocasionar consecuencias perniciosas, dependiendo si la norma penal sometida al control de constitucionalidad perjudica o beneficia al reo. En el primer caso, la declaración de inconstitucionalidad crea un vacío normativo de efecto despenalizador, que no solo opera hacia al futuro, sino también, al menos para parte de la doctrina, hacia el pasado ${ }^{14}$. Además, esta despenalización puede plantear, paradójicamente, una colisión con la obligación de revertir la concurrencia de una inconstitucionalidad por omisión, es decir, una desprotección penal injustificada del bien jurídico protegido ${ }^{15}$. En el segundo caso, por ejemplo, si la disposición invalidada establece una causa de justificación

\footnotetext{
11 Bustos y Hormazábal (2012) p. 127.

12 Bunzel (2007) p. 155.

13 López (2004) p. 466.

14 En concreto nos referimos la posibilidad de aplicar retroactivamente la jurisprudencia del TC que favorezca al reo. Véase respecto de Chile, Caballero (2006) pp. 177-193.

15 Así, la STC español 111/1993, de 25 de marzo -donde el recurrente había presentado un recurso de amparo por infracción del mandato de certeza, por entender que se le había condenado a partir de una interpretación analógica en contra del reo del artículo 321.1 del antiguo Código penal, que castigaba el ejercicio de actos propios de una profesión sin poseer el correspondiente "título oficial"- acudió a una ICC del término citado en el sentido de que este solo podía ser entendido como "título académico oficial", es decir, como título universitario. La imprecisión en la redacción del tipo penal no podía conducir a una declaración de inconstitucionalidad que despenalizara todo intrusismo profesional, es decir, incluido el ejercido sin título universitario, por lo que el TC decidió consolidar esta interpretación restrictiva.
} 
o exculpación, este vacío produce recriminadores, aunque solo de carácter prospectivo y no retroactivo.

Estos conflictos que hemos detallado someramente han llevado a parte de la doctrina a entender que el mandato de certeza no está estructurado como una regla, sino como una suerte de principio o regla (derrotable) que se encuentra en tensión con otros derechos o bienes constitucionales. Así, la restricción del Art. 19, inc. 6 CPR supone que debe existir una suerte de ponderación entre la consecución de precisión, claridad y la preservación de otros bienes jurídicos, cuya protección encuentre alguna raigambre en términos constitucionales ${ }^{16}$.

Con independencia de la corrección de esta propuesta desde la óptica de la dogmática de los derechos fundamentales y la teoría del derecho, que podríamos considerar como un supuesto de conflicto constitucional en abstracto ${ }^{17}$, esta comprensión del mandato de certeza puede difuminar de facto el contenido de esta garantía, ya que al TC le resulta especialmente cómodo encontrar un bien jurídico de raigambre constitucional para enervar esta garantía constitucional. Por esto, si aceptáramos la posibilidad de ponderar el mandato de certeza con otras normas constitucionales, entonces resulta necesario establecer unas reglas de ponderación para evitar una aplicación arbitraria por parte del legislador penal y el Tribunal Constitucional. Así, tenemos aquella que establece que a mayor restricción de libertad generada, tanto en el injusto penal, como en la consecuencia jurídica, mayor claridad, precisión u concreción deberá exigirse en la descripción de la norma penal y, por tanto, mayores son las posibilidades de declararla inconstitucional por infringir el mandato de certeza ${ }^{18}$. En todo caso, véase que aquí no nos encontramos ante un caso de conflicto concreto, sino por una ponderación abstracta de constitucionalidad. En este sentido, si la norma penal, imprecisa debido a un conflicto constitucional, supera el mínimo de certeza exigido por la Constitución, entonces el TC a través de una ICC podría ampliar o reducir su contenido normativo de tal forma que ambos principios constitucionales se vean garantizados en la mayor medida posible.

\section{EL CONFLICTO INTERNO EN EL CUMPLIMIENTO DEL MANDATO DE CERTEZA Y SU INCIDENCIA EN LA ICC}

A partir de la comprensión del mandato de determinación establecida por el TC español como la necesidad de que las normas penales sean concretas, precisas, claras e inteligibles, la doctrina ha extrapolado sus diversos fines o fundamentos. La claridad e inteligibilidad de los textos normativos conectan con el fundamento de la previsibilidad o seguridad subjetiva, entendida esta como posibilidad del conocimiento efectivo de la norma penal por parte de los ciudadanos (cognoscibilidad) ${ }^{19}$. La precisión se vincula con el

\footnotetext{
16 López (2004) p. 469. En Chile, véase Ossandón (2009) pp. 464-471.

17 Véase en extenso, MarTínez (2007) pp. 59-144.

18 OSSANdón (2009) p. 470.

19 Se descarta por tanto la concepción de la seguridad subjetiva como conocimiento efectivo del injusto penal. También se descarta el principio de culpabilidad como fundamento del mandato de certeza. En primer lugar, porque el principio de culpabilidad solo comprende el conocimiento (potencial) del injusto y no de la punibi-
} 
principio democrático y el de separación de poderes, así como el de seguridad jurídica en sentido estricto ${ }^{20}$, que proporciona la necesaria vinculación de los jueces con el imperio de la ley. Y la concreción, entendida como la suficiente individualización de ley penal, permite una aplicación igualitaria de esta.

Como primera regla interpretativa, el TC si opta por solucionar los problemas de certeza de una norma penal a partir de una ICC, debería, en la medida de lo posible, que esta contribuya a una mayor claridad, precisión y aplicación igualitaria de esta. Pero en ocasiones, esta posibilidad no es posible. La consecución de que una ley sea clara y fácil de comprender para todos los ciudadanos, de forma de que estos puedan adecuar su conducta a futuro; precisa o exacta para lograr la efectiva vinculación de los poderes del Estado a la ley penal; y, a la vez, concreta para asegurar una aplicación igualitaria no siempre resulta posible. Así, por ejemplo, más claridad no supone siempre más precisión. Tomando como ejemplo el delito de hurto, la descripción de la conducta como "no hurtarás" o "robarás" resulta mucho más clara para el ciudadano lego en derecho que la establecida en el Art. 432 CP que, sin duda, resulta mucho más precisa para los operadores jurídicos.

El cumplimiento del mandato de determinación no solo conlleva mayores cotas de seguridad jurídica, tanto en su dimensión objetiva como subjetiva, sino también a una aplicación más igualitaria del derecho penal. Navarro entiende que la fundamentación del mandato de determinación en el principio de igualdad posee un ámbito de aplicación autónomo respecto del resto de las fundamentaciones anteriormente señaladas. Puede suceder que una norma penal, a pesar de ser precisas y clara, adolezca de una excesiva generalidad que permita castigar con una misma pena supuestos que presentan un contenido valorativo muy diferente. La igualdad en la aplicación de la ley encuentra en el principio de abstracción el punto de conexión entre el principio de igualdad y el de legalidad ${ }^{21}$. Esto significa que la descripción de una ley deber ser lo suficiente abstracta para que, a su vez, permita identificar los rasgos esenciales de desvaloración: una cosa es que la exigencia de abstracción impida referirse a un supuesto de hecho concreto y otra bien distinta es que la decisión le-

lidad, y, en segundo lugar, porque el mandato de certeza se mueve en la relación entre Estado y ciudadano y, por tanto, no se ha personalizado en un determinado autor. Equiparar el mandato de certeza con el principio de culpabilidad supondría admitir una ley sumamente imprecisa, puede considerarse constitucional si, en el caso concreto, el imputado tenía la posibilidad o, incluso, el deber de conocerla. Véase, un estudio crítico de la jurisprudencia del Tribunal Constitucional chileno en Van Weezel (2011) pp. 30 y ss. Ahora bien, al exigirse un conocimiento potencial, se produce una objetivación del fundamento del mandato de certeza en la seguridad subjetiva. Esto supone, en último término, la posibilidad de que los ciudadanos puedan acceder al conocimiento de la ley penal a través de los especialistas (jueces, defensores, fiscales, etc.) y, por tanto, las diferencias entre la seguridad objetiva y subjetiva se diluyen. NAVArRo (2010) pp. 28-29. En el mismo sentido, Calderón, entiende que "las exigencias que la concepción objetiva de la seguridad jurídica plantea, en el fondo, no son sino requisitos necesarios para hacer realidad la concepción subjetiva de la misma”. CALDERón (2009) pp. 188.

20 Existen en la doctrina varias concepciones del principio de seguridad objetiva o sentido estricto. A efectos de este estudio, tomamos como referencia la propuesta de Pérez Luño quien la desglosa en dos planos: la corrección estructural que implica una adecuada formulación de las leyes, lo que se traduce en que estas deben ser claras, sin lagunas, estrictas, irretroactivas y estables; y la corrección funcional, que importa la sujeción de los poderes públicos y de los ciudadanos al bloque de la legalidad, evitando la arbitrariedad en la actuación de aquellos y la transgresión de las normas por parte de estos. Pérez (1994) p. 31.

21 Navarro (2010) pp. 45-48. 
gislativa alcance tal nivel de generalidad que llegue a impedir el reconocimiento en la ley de este mismo hecho concreto. El empleo de la abstracción facilita, en mucho, la averiguación de los casos que, por ser iguales, exigen un tratamiento igual. Solo a través de la abstracción es posible determinar dónde están los rasgos esenciales y dónde los accidentales de los supuestos de hecho concreto ${ }^{22}$.

El caso del Art. 373 CP no solo adolece de precisión, ya que no determina con un lenguaje jurídico adecuado sus condiciones de aplicación, sino que, al estar redactado de una manera general y extensa, abarca gran cantidad de conductas de distinto desvalor; es decir, el legislador no ha concretado el sector de las relaciones sociales merecedoras de esta protección penal. En otras palabras, no ha establecido las características esenciales que permitan una aplicación de esta ley de manera igualitaria, ya que este precepto abarca conductas muy dispares desde un punto de vista valorativo y, por tanto, puede acarrear penas desproporcionadas. Véase aquí la estrecha relación con el principio de seguridad jurídica, ya que en ambas pretenden evitar una aplicación arbitraria del derecho penal.

A la vez, no siempre con una regulación más concreta, esto es, que permita identificar los rasgos esenciales de desvaloración (igualdad en la aplicación de la ley) se consigue al mismo tiempo una regulación más determinada en el sentido de más precisa (seguridad objetiva). Así, la prohibición de entrar a un restaurante con animales es más precisa y, sin embargo, es menos concreta que la de entrar con animales molestos, que resulta más concreta, ya que delimita en mejor medida las relaciones sociales merecedoras de protección, pero resulta menos precisa ${ }^{23}$. Navarro pone como ejemplo la descripción de la cláusula de cierre del delito de colaboración con banda armada establecida en Art. 576. 2 CP español en relación a la establecida en el derogado Art. 174 bis a CP de 1973. En este último, se establecía como típica "cualquier otra forma de cooperación, ayuda o mediación, económica o de otro género, con las actividades de las citadas bandas o elementos"; mientras que el actual delito de colaboración con banda armada se describe como "cualquier otra forma equivalente $^{24}$ de cooperación ayuda o mediación, económica o de otro género, con las actividades de las citadas bandas armadas, organizaciones o grupos terroristas". Véase que, en esta cláusula abierta se añade un requisito de equivalencia que contribuye a una mayor concreción del tipo penal, ya que se exige una peligrosidad equivalente a la de las conductas descritas en el propio CP español y, por tanto, evita una aplicación no igualitaria de la ley, pero en cambio le resta exactitud al texto. En estos casos, Navarro sostiene que -ya que el mandato de determinación trata de delimitar el injusto penal específico, comprendiendo los rasgos esenciales- la precisión debe ceder, aunque no de forma ilimitada, a la concreción ${ }^{25}$. A lo anterior debemos añadir que el injusto penal se encuentra estrechamente con la teoría del bien jurídico, en especial, con la descripción de su lesión o puesta en peligro: la concreción determina en mejor medida la puesta o lesión del bien jurídico protegido y, por tanto, prima sobre su exactitud.

\footnotetext{
22 Gimbernat (2009) pp. 91 y ss.

23 Ferreres (2002) p. 74.

24 Negrita del autor.

25 Navarro (2010) p. 56.
} 
También entre las exigencias de claridad y de concreción de la ley se dan situaciones de conflictos. Puede suceder que un término fácilmente comprensible por los ciudadanos adolezca de una excesiva generalidad. En estos casos, la concreción prima sobre la claridad en aras de lograr una mayor garantía frente a la arbitrariedad y unas mayores cotas de igual$\mathrm{dad}^{26}$.

Por último, se puede dar una tensión entre el mandato de previsión (seguridad subjetiva) con los de precisión (seguridad objetiva) y concreción (igualdad en la aplicación de la ley). Un caso paradigmático lo encontramos en las leyes penales que favorecen al reo. Si se entiende el principio de legalidad únicamente como una garantía del ciudadano de que pueda conocer las consecuencias penales de sus acciones, entonces se puede concluir que en estos casos podrían decaer, o al menos, no aplicarse con la misma intensidad, la relación de prevalencia de la precisión respecto a la previsión. Pero si persiste el interés de que la ley no se aplique de forma arbitraria y que, tampoco vulnere el principio de igualdad en la aplicación de la ley, entonces puede suceder que una norma penal poco clara en el sentido de no cognoscible y que favorece al reo, puede derivar en una aplicación arbitraria y no igualitaria de esta ${ }^{27}$. Así, podemos poner a modo de ejemplo de la atenuante de irreprochable conducta anterior (Art.11 CP), que se encuentra redactada de forma poco clara (ya que el ciudadano no conoce qué conductas anteriores pueden ser consideradas como irreprochables) permite, a partir, de un argumento a favor el reo, ampliar el ámbito de aplicación de esta figura, pero a la vez, puede derivar en una aplicación arbitraria o no igualitaria de la ley penal. Otro ejemplo donde la seguridad objetiva y la igualdad en la aplicación de la ley cobran especial relevancia, es respecto a las causas de exclusión de la culpabilidad. Si partimos del hecho de que en la mayor parte de los casos el sujeto tiene alterada la comprensión y la conciencia, la certeza jurídica en su dimensión de claridad se ve comprometida y, por tanto, resulta difícil que un ciudadano oriente su conducta a la prohibición establecida en el injusto penal. Por tanto, la descripción precisa y abstracta de las causas de exculpación y de las medidas de seguridad aparejadas a estas cobra una mayor relevancia respecto de la claridad.

La resolución de estos conflictos no solo tiene una repercusión directa en la descripción de las leyes penales, sino también a la hora de controlar su constitucionalidad y, en nuestro caso, en la determinación de las condiciones interpretativas de constitucionalidad. Así, el TC en el momento de interpretar la norma incierta deberá determinar cuál tiene prevalencia en caso de conflicto entre ellas, excluyendo, en todo caso, la posibilidad de limitarse a elegir uno u otro fin de manera aleatoria ${ }^{28}$. De esta manera, si se entiende que lo prioritario es vincular de forma efectiva a los jueces al imperio de la ley, frente a la obligación de informar a los ciudadanos, sería recomendable que la ICC incorporará al contenido normativo de la norma penal conceptos técnico-jurídicos, aunque esto suponga una menor inteligibilidad del texto para los ciudadanos. Ahora bien, estos fines o fundamentos, salvo la seguridad subjetiva, se encuentran interconectados, en el sentido de que la consecución

26 Navarro (2010) p. 56.

27 Navarro (2010) p. 60.

28 Navarro (2010) p. 22. 
de uno de ellos favorece, normalmente, la consecución del resto de ellos. Así, una norma más precisa garantiza, no solo la exclusión de la arbitrariedad (seguridad objetiva), sino también una aplicación más igualitaria de la ley, aunque, como hemos visto, esta interacción no siempre ocurre ${ }^{29}$.

De acuerdo con lo expuesto, podemos establecer que el TC a la hora de realizar una ICC de una norma penal con el fin de evitar que esta sea declarada inconstitucional por infringir el mandato de certeza, deberá tener presente el siguiente orden de prevalencia.

En primer lugar, el TC deberá detectar qué característica del mandado de certeza se encuentra comprometida: la precisión, la claridad o la igualdad en la aplicación de la ley. En este caso, la ICC debería centrarse en solventar o mitigar la característica comprometida. En segundo lugar, entendemos que las exigencias de precisión (seguridad objetiva) y concreción (aplicación igualitaria de la ley) deben primar en caso en conflicto con el de claridad (seguridad subjetiva). Esto supone que si el TC decide acudir a una ICC esta deberá centrarse en precisar y concretar la norma más que en aclararla.

\section{LA INTERPRETACIÓN CONFORME CON LA CONSTITUCIÓN COMO MECANISMO DE DETERMINACIÓN DE LAS NORMAS PENALES}

Como hemos apreciado en el anterior apartado, la ICC encuentra uno de sus mejores caldos de cultivo en los tipos penales abiertos o en aquellos que contienen elementos normativos-valorativos, ya que puede constituir un medio para precisar y clarificar normas penales redactadas de manera imprecisa y poco claras. Cuando el TC quiere salvar una ley por ser imprecisa, poco clara o ambigua a través de una ICC está estableciendo una condición constitucional interpretativa que se materializará a través de la inclusión de un determinado contenido normativo (dimensión positiva) o expulsión de una o varias interpretaciones (dimensión negativa). Por ejemplo, si el TC manifiesta, con el fin de evitar una declaración de inconstitucionalidad, que el término "buenas costumbres" comprendido en el Art. 373 CP debe entenderse solo en el ámbito de la sexualidad u orientación sexual, vemos claramente, que estamos ante una condición interpretativa, similar a la establecida en la ICC.

Ahora bien, parte de la doctrina comparada ha cuestionado la pertinencia de la ICC como mecanismo de determinación de las normas penales. En la doctrina estadounidense, Berry, en un reciente estudio, mantiene que el canon interpretativo conocido como constitutional avoidance no debería aplicarse en los casos de relacionados con el mandato de certeza (void-for vagueness). Cuando la Corte Suprema aplica el constitutional avoidance para determinar si una norma penal cumple con el mandato de certeza, en vez de determinar si su descripción resulta demasiado vaga o imprecisa; es decir, si carece en absoluto de un significado inteligible, lo que hace realmente es reescribir la ley modificando su contenido. A partir de una comprensión del mandato de certeza como la razonable oportunidad de conocer qué conducta es considerada como criminal, además de constituir una garantía para evitar la aplicación arbitraria o discriminatoria de la norma penal, el autor manifiesta que su cumplimiento no puede depender de la decisión de un tribunal, sino del propio texto

29 Navarro (2010) p. 60. 
legal, el cual debe contener un mínimo de precisión y certeza. Además, Berry añade que la utilización de este canon para resolver cuestiones de certeza confunde los conceptos de vaguedad y ambigüedad. La utilización de este canon para resolver cuestiones de certeza atenta, paradójicamente contra la doctrina del judicial restraint, ya que lo que realmente se hace es reescribir la ley con la pretensión de salvarlo de una declaración de inconstitucionalidad.

No obstante, la propuesta de este autor es discutible, ya desde su propia comprensión del presupuesto de hecho de este canon interpretativo como un caso de ambigüedad normativa. La posibilidad de acudir a una ICC no solo concurre cuando dos más interpretaciones del texto infraconstitucional, donde al menos una de ellas resulta inconstitucional y otra es válida (classical avoidance), sino también cuando la interpretación más correcta, desde el punto de vista de los cánones clásicos, plantea series dudas sobre su constitucionalidad (mordern avoidance). En cambio, si compartimos con el autor que la ICC, como mecanismo para solventar cuestiones de certeza, debe tener un límite: si la disposición normativa no contiene un mínimo de precisión, concreción y, en menor medida, claridad, el TC debe declarar su inconstitucionalidad.

Relacionado con lo suscrito por el autor citado, una cuestión interesante en nuestro sistema penal es si el mandato de certeza abarca también los problemas de ambigüedad, ya que en nuestro Derecho procesal penal contamos con el recurso de nulidad que, precisamente, está ideado para solventar la situación de inseguridad que se produce cuando existen interpretaciones divergentes sostenidas en diversos fallos de las Cortes de Apelaciones (Art. 376, inc. $2^{\circ} \mathrm{CPP}$ ). Aquí, claramente, se plantea una tensión institucional con la Corte Suprema y entendemos, de acuerdo a lo sostenido en la introducción de este estudio, que el TC solo debería determinar si en estos casos la interpretación realizada por las Cortes de Apelaciones o por la Corte Suprema resulta contraria a la Constitución. En cambio, la mejor interpretación posible conforme con la Constitución corresponde a los tribunales ordinarios.

En la doctrina española, Ferreres manifiesta que cuando el TC precisa o clarifica una norma penal, para de esta forma salvar su validez, estamos ante un supuesto distinto del que se conoce como "interpretación conforme", pues que aquella no ofrece ninguna fundamentación (material-constitucional) a favor de una u otra de las interpretaciones posibles: "la Constitución es indiferente al respecto, lo único que quiere es claridad en la ley". Así, el autor pone como ejemplo, la STC español 53/1994, donde de acuerdo con la normativa de pesca era posible realizar dos interpretaciones sobre cuándo una reiteración de faltas administrativas se consideraba como delito; mientras que una establecía la necesidad de cuatro infracciones idénticas, la otra no exigía una identidad entre ellas. El citado autor manifiesta que ambas interpretaciones son constitucionales y la única exigencia es la elección de una de ellas para superar la indeterminación de la norma y a la vez conservar su validez.

Por el contrario, entiendo errónea o, al menos, confusa la diferencia entre la ICC y la interpretación con el fin de clarificar o precisar una norma penal se circunscriba en una supuesta neutralidad de esta última. En primer lugar, como he señalado, el TC a la hora de determinar o precisar una norma penal que adolece de falta de certeza puede encontrarse ante un conflicto entre los diferentes fundamentos o fines del mandato de certeza. Así, puede optar por salvaguardar la seguridad jurídica objetiva (evitar la arbitrariedad) o proteger la seguridad subjetiva (facilitar la comprensión del justiciable). Como puede apreciarse esta 
elección es cualquier cosa menos neutral. En segundo lugar, porque cuando el TC realiza una interpretación de una norma penal cuestionada por su falta de certeza no puede inhibirse del resto de los derechos fundamentales y principios penales. Así, en el ejemplo citado por el autor, el principio de intervención mínima y el carácter fragmentario del derecho penal inclinan la balanza a favor de la interpretación de las "cuatro infracciones idénticas" o, al menos, de la misma gravedad.

Ahora bien, delimitar los casos en que un problema de indeterminación puede ser subsanado por los tribunales constitucionales mediante una ICC no resulta sencillo. Desde una perspectiva analítica, podemos establecer tres grupos de casos. El primero, referido a los casos más graves o intolerables de indeterminación, donde la única respuesta posible es la declaración de inconstitucionalidad; el segundo, aquellos casos (graves), donde la falta de taxatividad pueda ser subsanada mediante una ICC; y, por último, los casos menos graves, donde la falta de determinación puede ser subsanada por los tribunales penales mediante la interpretación y un adecuado sistema de precedentes.

Un punto de partida es la propuesta mantenida por la doctrina alemana entre núcleo de significación y campo de significación. El núcleo de significación se compone de los casos que, indudablemente, se subsumen en el concepto o signo del lenguaje. En cambio, el campo de significación abarca aquellos casos en que no existe una seguridad previa sobre su subsunción en el concepto. Esta situación se agrava cuando este campo de significación solo puede determinarse a partir de juicios valorativos. Así, los casos en que el campo de significación ocupa la mayor parte de los posibles casos subsumibles en una determinada norma penal es donde debería plantearse con mayores probabilidades una declaración de inconstitucionalidad. Además, deberá afectar gravemente a todas o a la mayor parte los principios que informan al mandato de certeza: la obligación de informar adecuadamente a los ciudadanos sobre un tema tan transcendental para sus derechos fundamentales como es el derecho penal; la vinculación de los poderes públicos al principio de legalidad; y la aplicación igualitaria del derecho penal ${ }^{30}$.

Así, por ejemplo, el Art. 373 CP constituye un firme candidato para una declaración de inconstitucionalidad por vulneración del mandato de certeza y, donde no cabría, por tanto, la posibilidad de una ICC para salvar su inconstitucionalidad. Así, la mayor parte de sus términos ("los que de cualquier modo ofendieren el pudor o las buenas costumbres con hechos de grave escándalo") forman parte del campo de significación, es decir, la mayor parte de los posibles casos subsumibles; la determinación de este campo solo puede ser llevado a cabo mediante juicios morales, y afecta a la mayor parte de los principios y fundamentos del mandato de certeza.

\section{LA TENSIÓN ENTRE EL PRINCIPIO DE CORRECCIÓN FUNCIONAL Y LOS MANDATOS DE LEX CERTA Y LEX STRICTA}

Una de las cuestiones más problemáticas que plantea la ICC en materia penal reside en el hecho de que permite una interpretación de la norma infraconstitucional más allá del sentido literal posible, pero este tipo de interpretación forzada de la ley se enfrenta

30 Véase, por todos, NaVArro (2010) pp. 62 y ss. 
con las limitaciones contempladas en los mandatos de lex certa y lex stricta. Efectivamente, mientras la ICC establece una carga interpretativa a favor del mantenimiento de las normas infraconstitucionales, incluso más allá del sentido literal posible, los mandatos materiales del principio de legalidad nos indican, por una parte, que las normas penales deben estar descritas con una mayor precisión y concreción por parte del legislador; y por otra, que los tribunales no pueden realizar interpretaciones analógicas en contra del reo, prohibición extensible al propio TC. En otras palabras, las posibilidades interpretativas conforme con la Constitución en materia penal pareciesen que se reducen en comparación con otras clases de normas.

En cuanto al mandato de lex certa, la posición deferente hacia el legislador deber ser matizada, ya que el argumento democrático también puede justificar un control de constitucionalidad más riguroso, es decir, una mayor predisposición a expulsar del ordenamiento jurídico el texto normativo. A través de un examen riguroso del mandato de certeza se estaría exigiendo al legislador democrático que asumiera la carga de deliberar y decidir con claridad, precisión y concreción acerca de los problemas colectivos, ya que ostenta una ventaja epistémica y democrática a la hora describirlos.

Otro límite a la posibilidad de recurrir a una ICC reside en la adopción de protecciones reforzadas en relación con algunos derechos fundamentales y, por tanto, existe un menor margen para que el TC acuda a este test de constitucionalidad como mecanismo de determinación. Un caso lo encontramos en las doctrinas estadounidenses de la "amplitud excesiva" (overbreadht) y de la "vaguedad" (vagueness) aplicables a los casos en que una norma limita la libertad de expresión. Así, respecto de la primera, cuando una norma que limita la libertad de expresión está descrita con una excesiva amplitud, no se aplica la solución ordinaria (una interpretación restrictiva conforme con la Constitución), sino una mucho más drástica: la inconstitucionalidad de la norma en su totalidad. La doctrina de la vaguedad exige una especial claridad en las normas que puedan afectar a la libertad de expresión. También aquí la consecuencia es la inconstitucionalidad de la norma en su totalidad ${ }^{31}$.

El mandato de lex stricta contempla las siguientes reglas interpretativas: la primera, la obligación del juez de aplicar la norma penal solo a los casos que resulten claros, es decir, excluyendo aquellos en los que existan dudas a la hora de subsumirlos bajo las condiciones de aplicación descritos en el supuesto de hecho típico; la segunda, la prohibición de analogía en contra del reo; la tercera, como excepción del primera regla, la posibilidad de la interpretación analógica a favor del reo; y la cuarta, en caso de duda sobre la interpretación correcta, aplicar aquella que resulta más favorable al reo . La cuestión que se plantea, por tanto, es qué medida la ICC debe respetar estas reglas interpretativas.

Si partimos de la premisa de que el TC tiene como principal cometido en materia de interpretación expulsar aquellos contenidos normativos que contradicen abiertamente la Constitución, entonces, la prohibición de analogía en contra del reo constituye el núcleo esencial de control de constitucionalidad en materia de lex stricta. Así, por ejemplo, no podría realizarse una ICC, donde la condición interpretativa de constitucionalidad es fruto de una interpretación analógica en contra del reo. En cambio, la posibilidad de interpretacio-

31 Berry (2014) p. 110. 
nes conforme a la Constitución que, claramente, vayan más allá del sentido literal posible y de la voluntad del legislador solamente puede admitirse en los casos en que favorezcan al justiciable, quedando, por tanto, proscritas las que perjudiquen al ciudadano. Además, desde una perspectiva institucional, el TC debe, en principio, respetar aquellas interpretaciones analógicas o in dubio pro reo realizadas por los tribunales ordinarios.

Ahora bien, esta regla interpretativa debe hacerse cargo de la distinción, aceptada por parte de la doctrina, entre la interpretación extensiva y la analogía en contra del reo. En este sentido, parte de la doctrina penal acepta la denominada interpretación extensiva, aunque esta perjudique al reo. Un lector familiarizado con nuestra jurisprudencia constitucional puede barruntar sin demasiada dificultad que el TC declarará de manera expresa o tácita que la ICC perjudicial al reo constituye una interpretación extensiva y no una analogía en contra del reo

\section{LA JURISPRUDENCIA COMO COMPLEMENTO A LA DETERMINACIÓN DE LAS LEYES PENALES}

Los tribunales constitucionales, con el fin no tener que declarar la invalidez de una ley sancionadora demasiada imprecisa, apelan en ocasiones a la jurisprudencia de los tribunales ordinarios y, en especial, a los tribunales superiores para decidir si una norma cumple con las exigencias del mandato de certeza. Por tanto, la determinación de si una norma penal cumple o no el mandato de certeza no debe atenerse solo al examen del precepto o disposición normativa, sino también a la jurisprudencia que en torno a ella han elaborado los tribunales ordinarios ${ }^{32}$. Si a esta afirmación, añadimos la consideración de que los propios tribunales constitucionales acuden a la ICC a la hora de resolver un problema de indeterminación normativa, entonces podemos atisbar que existe una nueva peculiaridad en la aplicación de esta técnica de control de constitucionalidad en materia penal ${ }^{33}$.

Si un determinado conflicto social o la protección de un bien jurídico protegido requieren para su protección la utilización de conceptos jurídicos indeterminada, estos

\footnotetext{
32 Véase en extenso, Ferreres (2002) pp. 153 y ss. A modo de ejemplo, véase la STC español 89/1993, donde se sostuvo que las expresiones "elementos terroristas" y "organizaciones terroristas" no eran indeterminadas, puesto que existía ya jurisprudencia del propio TC y de la jurisprudencia ordinaria que permitía una "delimitación suficiente, clara y precisa” de esas expresiones" (FJ3). La Corte Suprema estadounidense ha declarado que cuando se ataca una disposición penal sobre la base de la doctrina de la "nulidad por vaguedad", no hay que examinar la disposición on its face, sino con su judicial gloss, es decir, con la jurisprudencia que en torno a ella han sentado los tribunales penales encargados de interpretarla. Así, véase entre otras sentencias de la Corte Suprema Estadounidense, WARD V. ILLINOIS, 431 US 767 (1977); WAINWRIGHT V. STONES, 414 US 21 (1973). Citadas por Ferreres (2002) p. 156, n. 5. El TC Federal Alemán ha declarado leyes penales suficientemente determinadas con el argumento de que la falta de certeza ha desaparecido de facto a través de la praxis jurisprudencial. Pero, a la vez, el propio TC y el Tribunal Supremo alemanes proclaman la prohibición al juez penal de "mejorar por sí una ley indeterminada". Kunlen (2012) p. 145. El TC de manera constante mantiene que, en el contexto del requerimiento de inaplicabilidad, "debe practicarse un examen concreto de si el precepto legal, invocado en una gestión pendiente y correctamente interpretado, producirá efectos o resultados contrarios a la Constitución». Véase, en el caso de una interpretación conforme con la Constitución, la STC Rol 2651/14, arts. 292 y 293 CP.

33 Kuhlen (2012) p. 143. Véase la jurisprudencia citada por el autor.
} 
cumplirían con el mandato de determinación siempre y cuando exista la posibilidad de una interpretación judicial que delimite sus contornos. En el mismo sentido, el TC español en su sentencia 15/1997, de 29 de septiembre (FJ 3) estableció que las cláusulas abiertas o necesitadas de complementación judicial son compatibles con el principio de legalidad siempre y cuando: 1) la concreción sea posible en virtud de criterios lógicos, técnicos o de experiencia; 2) exista una fuerte necesidad de tutela y sea imposible otorgarla en términos más precisos; 3) concurra una motivación del juez o tribunal sobre la interpretación de la cláusula. Además, establece un límite al nivel de indeterminación aceptable constitucionalmente: que la descripción del tipo penal "no aboque a una inseguridad jurídica insuperable con arreglo a los criterios interpretativos (STC 69/1989, de 20 de abril, FJ 1) ) $^{34}$.

La incorporación de la jurisprudencia sobre el texto normativo penal a la hora de determinar si cumple con el mandado de certeza resulta razonable en los supuestos en que el legislador ha querido que el juez concrete o precise este de acuerdo con las circunstancias del caso. Esto supone que los tribunales ordinarios, al aplicar la norma al caso concreto, deben establecer su contenido normativo a través de un sistema de precedentes o de unificación de jurisprudencia. Por esta razón, cuando los tribunales de justicia no han sido capaces de establecer una jurisprudencia unificada o existen dos o más líneas jurisprudenciales opuestas sobre un texto normativo penal descrito de manera indeterminada, resulta plausible afirmar que no se cumple con el mandato de certeza ${ }^{35}$.

Si se acepta esta delegación en la determinación de las normas penales, entonces, la jurisprudencia de los tribunales encargados de unificar esta debe ser vinculante, tanto en el sentido vertical como horizontal ${ }^{36}$. En otras palabras, si entiende la jurisprudencia como complemento del mandato de certeza, entonces habrá que reconocer sin ambages que la jurisprudencia debe tener carácter vinculante" ${ }^{37}$.Ahora bien, debemos tener presente que el grado de vinculación de la jurisprudencia en nuestro sistema procesal penal resulta, especialmente problemático ${ }^{38}$, por lo que el TC debería ser muy cuidadoso a la hora de acudir a esta como fundamento para determinar si una norma penal cumple con las exigencias del mandato de certeza.

Un caso emblemático es, a mi entender, el conocido fallo de la Corte Suprema de 19 de junio de 2006, Rol N²005-05 sobre el delito de microtráfico, donde estimó que correspondía a los tribunales a quo establecer en cada caso concreto cuándo nos encontramos ante una pequeña cantidad de droga, y no a la propia Corte Suprema a través de criterios generales o pruebas indiciarias ${ }^{39}$. Desde esta posición, el TC tendría un fundamento adicional para determinar la inconstitucionalidad del Art. 4 de la Ley 20.000, debido a que los

\footnotetext{
34 En el mismo sentido, STC 88/2003, de 19 de mayo.

35 Ferreres (2002) pp. 156-159.

36 Ferreres (2002) p. 67.

37 Ferreres (2002) p. 159.

38 Sobre la problemática del valor del precedente y la función de unificación de jurisprudencia en el derecho penal chileno, véase, Couso y Mera (2011) pp. 97 y ss.; Echeverría (2013) pp. 83 y ss.

39 Contra MEZA (2005). Este fallo entendió el término "pequeña cantidad", no como un elemento normativo de la conducta, si no como un elemento "regulativo", refiriéndose a aquellos elementos que, contemplados en la descripción típica de la conducta por el legislador, implican un mandato para el juez de decidir el caso a partir
} 
tribunales ordinarios, en concreto la Corte Suprema, no han sido capaces de establecer una jurisprudencia unificada sobre qué se entiende por una "pequeña cantidad" de drogas.

Pero, frente a esta fundamentación material constitucional, en este caso, referido a la protección de la seguridad jurídica, se opone un argumento de tipo institucional: los tribunales constitucionales no deberían desempeñar la función de unificación de jurisprudencia, cometido que corresponde institucionalmente a los tribunales ordinarios superiores. La cuestión, por tanto, es determinar si el requerimiento de inaplicabilidad puede ostentar alguna función en la unificación de la jurisprudencia de los tribunales ordinarios. La respuesta, a mi entender es afirmativa, si el TC se ciñe a comprobar si estos han establecido unos criterios interpretativos sobre la norma penal que permita ofrecer una mínima seguridad jurídica. Así, el mandato de certeza se vería cumplido con una norma penal relativamente imprecisa si la jurisprudencia de las Cortes de Apelaciones o, en su defecto, la Corte Suprema ha concretado su significado ${ }^{40}$. Pero, esta propuesta se topa con una objeción democrática, ya que, al menos en parte, los tribunales ordinarios inferiores no estarían sometidos a la ley, sino a la interpretación de los tribunales superiores. Ante esta objeción el propio Ferreres Comella manifiesta que la descripción de una norma penal indeterminada supone una decisión soberana del legislador de delegar en los tribunales ordinarios completar o precisar su contenido normativo. Además, el Parlamento siempre es libre de rectificar mediante una reforma legislativa una determinada interpretación jurisprudencial ${ }^{41}$. Ahora bien, como reconoce el autor citado, existen casos en que, a pesar de contar con una jurisprudencia unificada, la norma penal en abstracto es per se contraria al mandato de certeza. Un ejemplo, a mi juicio, lo encontramos nuevamente en el Art. 373 CP, ya que supone una dejación absoluta de la función del legislador penal a la hora de describir el contenido esencial de la conducta desvalorada y, por tanto, amerita su expulsión del Ordenamiento jurídico, con independencia del esfuerzo de los tribunales penales de limitar su aplicación y adecuarlo a los derechos fundamentales. En otras palabras, si entendemos que el mandato de lex certa constituye un mandato destinado al legislador, este no puede ser soslayado en todo caso a través de una jurisprudencia unificada.

La cuestión que surge a continuación es si el TC puede acudir a la ICC como mecanismo para subsanar la ausencia de jurisprudencia o uniformidad de esta. Aquí, de nuevo, se presentaría un conflicto constitucional con los tribunales superiores de justicia encargados de unificar la jurisprudencia. Como principio general, el TC debería solo expulsar de la comunidad jurídica aquellas interpretaciones por parte de los tribunales ordinarios que resultan claramente contrarios a la Constitución (ICC negativa) y, de esta manera, contribuiría de manera indirecta a su unificación. La cuestión se complica en los casos en que el legislador claramente ha delegado en los tribunales ordinarios la concreción y precisión de una norma penal, como, por ejemplo, un tipo penal abierto. En este caso, sí estaría

de sus particularidades concretas, renunciando, entonces, el legislador a regular la conducta. Véase una posición crítica a esta sentencia en: RuIz (2009) pp. 411 y ss.

40 En el mismo sentido, Ferreres (2002) pp. 160-166.

41 Ferreres (2002) pp.167-173. En todo caso, la jurisprudencia vinculante no soluciona algunos problemas. Así, tenemos el caso de leyes penales indeterminadas que utilizan expresiones no arraigadas en la cultura jurídica. 
justificado acudir a una ICC positiva, pero también resultaría plausible la declaración de inconstitucionalidad para que, de esta manera, el legislador democrático redacte una nueva norma penal que cumpla con los requisitos de certeza. Aquí, el TC debe determinar si la norma penal en abstracto es per se contraria al mandato de certeza, atendiendo, como hemos visto, a la teoría del núcleo y campo de significación o a la necesidad de protección del bien jurídico. De la misma manera, estaría justificada acudir a una ICC positiva en los casos en que solo cabe una interpretación posible para evitar la declaración de inconstitucionalidad de la norma penal.

\section{UNA BREVE REFERENCIA A LA JURISPRUDENCIA DEL TRIBUNAL CONSTITUCIONAL CHILENO}

A la fecha de la elaboración de este estudio, encontramos un fallo (STC Rol 2651-14 de 23-12-2014) en el que expresamente se plantea un problema de certeza de una norma penal y donde el TC acude a una ICC, aunque, como veremos a continuación, esta última afirmación debe matizarse en varios sentidos. Pero antes de entrar al estudio de esta sentencia, debemos advertir que el resto de las ICC en materia penal realizadas por el TC, si bien no tuvieron como finalidad principal solventar un problema de certeza, sino el cumplimiento de otros principios o límites penales como el de culpabilidad y de protección de bienes jurídicos, la mera interpretación de las normas infraconstitucionales puede otorgar un mayor grado de certeza. Así, por ejemplo, en la STC Rol 993- 9, relativa al delito de tráfico de pequeñas cantidades, al establecer que estamos ante un delito de peligro concreto, otorga un mayor grado de certeza a esta figura penal, ya que el enunciado normativo de esta figura no establece expresamente el grado de peligrosidad de la conducta.

La STC Rol 265-14 dirimió si la expresión «atentar contra el orden social» establecida en el delito de asociación ilícita del Art. 292 CP vulneraba el principio de tipicidad reconocido en el Art. 19. 3, inc. $8^{\circ} \mathrm{CPR}$. El TC estableció que este precepto no vulneraba el citado precepto constitucional, fundamentado, entre otras razones, en la existencia de varias interpretaciones de este precepto conforme con el principio de tipicidad.

Así, y de acuerdo con la doctrina y jurisprudencia ordinaria, considera que esta expresión debe interpretarse, de acuerdo con el Art. 293 CP, en el sentido que estos atentados con el orden social deben constituir crímenes que o simples delitos ${ }^{42}$. Además, a partir de esta comprensión, la sentencia incorpora dos variantes interpretativas realizadas por la doctrina y la jurisprudencia que, a juicio del TC, resultan conformes con la Constitución. La primera variante interpretativa, entiende que, de acuerdo con parte la doctrina, la expresión «orden social» resulta vaga e imprecisa y, esta ha sido la razón de que el Proyecto de Código Penal, presentada por el Poder Ejecutivo en el año 2014, elimina esta expresión y solo se exige la finalidad o la comisión de delitos. Por tanto, esta posición elimina esta última referencia, exigiendo solamente la finalidad o la comisión de crímenes o simples delitos. La segunda variante interpretativa entiende que resulta posible delimitar, a partir del bien

42 Considerando $13^{\circ}$. 
jurídico protegido por cada figura delictiva, qué delitos (crímenes y simples delitos) atentan el «orden social» ${ }^{43}$.

De manera sucinta, esta sentencia amerita los siguientes comentarios:

En primer lugar, debemos señalar que nos encontramos ante una interpretación meramente declarativa, en la que el TC solo reproduce los contenidos normativos, que ya se encontraban presentes en la praxis jurisprudencial ordinaria, en contraposición de los pronunciamientos interpretativos auténticos, en los que el TC introduce ex novo elementos que condicionan la comprensión del precepto legal más allá de la interpretación asentada en otras instancias jurisdiccionales.

En segundo lugar, no toda sentencia que contenga una o varias interpretaciones posibles de la ley de acuerdo a la Constitución puede catalogarse como una sentencia interpretativa en el sentido que habitualmente se le brinda a esta variante de sentencia manipulativa. Si el criterio determinante para identificar este tipo de sentencias fuera la existencia o no de interpretaciones de las normas infraconstitucionales, este tipo de sentencias carecerían de autonomía conceptual, ya que todas las sentencias del TC en mayor o menor medida realizan una interpretación de una ley. Por tanto, su peculiaridad reside en establecer «factores interpretativos condicionantes». En este sentido, la ICC puede consignarse en el fallo o derivarse de los propios fundamentos de la sentencia. Incluso, podemos encontrar casos en que el TC no realiza ninguna mención expresa a un condicionamiento interpretativo de la ley sometida al control de constitucionalidad, sino que se deriva de la lectura del texto del fallo y que de algún modo los operadores jurídicos entienden como vinculante. Otra de las características que otorgan autonomía conceptual a la ICC es que esta vaya más allá del sentido literal posible de la norma infraconstitucional. En estos casos, solo el TC constitucional estaría legitimado para realizar este tipo de interpretación para, de esta manera, evitar una declaración de inconstitucionalidad. La cuestión, por tanto, es si este fallo contiene un factor interpretativo condicionante. Con carácter general, el TC reconoce como condición interpretativa general que, en todo caso, el delito de asociación ilícita debe tener la finalidad de cometer crímenes o simples delitos. Además, considera que las dos variantes interpretativas del Art. 292 CP no vulneran el mandato de lex stricta. Así, en la segunda variante interpretativa aplica la teoría del bien jurídico para interpretar un enunciado normativo y, en la primera, manifiesta que "la extensión de término es tal que no puede desecharse la afirmación que todo delito es, en su medida, un atentado con el orden social»y, por tanto, este requisito resulta superfluo ${ }^{44}$. No obstante, en este último caso, el límite del sentido literal posible, al menos, se encuentra más comprometido, ya que se suprime de facto una condición de aplicación en el presupuesto de hecho del Art. 292 CP.

En tercer lugar, el TC opta por una concepción de la ICC más deferente con el Poder judicial. Así, establece que su función no es establecer la mejor interpretación posible, sino «examinar la normativa cuestionada a la luz de sus posibles interpretaciones correctas y si alguna de estas resulta contrarias a la Constitución ${ }^{45}$.

\footnotetext{
43 Considerando $22^{\circ}$ a $24^{\circ}$.

44 Considerando $16^{\circ}$.

45 Considerando $8^{\circ}$.
} 
En cuarto y último lugar, si comparamos las dos variantes interpretativas mencionadas con anterioridad, podemos apreciar un conflicto interno entre los diferentes fundamentos del mandato de certeza a la hora de interpretar la expresión «orden social». Ambas variantes plantean problemas de claridad, ya que para el justiciable resulta igualmente indeterminado que el delito base se concrete a partir del bien jurídico protegido o a través de la pena impuesta, que es la forma de determinar cuándo estamos ante un crimen o simple delito (Arts. $3^{\circ}$ y $21 \mathrm{CP}$ ). En cuanto a la precisión, esta última variante resulta menos problemática para los operadores del derecho, ya que requiere solamente determinar la penalidad del delito base. Y en cuanto a la aplicación igualitaria de la ley, esta última variante interpretativa resulta también menos problemática que la primera, puesto que, a partir de la expresión "orden social», existe un mayor peligro de aplicar esta figura penal de manera arbitraria, por ejemplo, por razones políticas, sin perjuicio, claro está, de que afecta a otros principios o límites penales como el proporcionalidad o fragmentariedad del derecho penal.

\section{CONCLUSIONES}

Como hemos intentado fundamentar en este estudio, la ICC constituye un mecanismo de control de constitucionalidad adecuado para solventar problemas de certeza en la descripción de normas penales. Ahora bien, esta técnica de control de constitucionalidad encuentra un límite insoslayable: si la disposición normativa no contiene un mínimo de precisión y claridad, el TC debe declarar su inconstitucionalidad y, por tanto, abstenerse de realizar una ICC.

En el contexto del modelo penal de seguridad ciudadana, la ICC debería adquirir una mayor relevancia como mecanismo corrector en los casos de sobreinclusión y de ausencia (injustificada) de certeza.

Si una norma penal imprecisa, debido a un conflicto constitucional, supera el mínimo de certeza exigido por la Constitución, entonces el TC a través de una ICC puede ampliar o reducir su contenido normativo de tal forma que los principios constitucionales en conflicto (seguridad y aplicación igualitaria de la ley versus una adecuada protección del bien jurídico protegido) se vean garantizados en la mayor medida posible.

En los casos de conflicto interno, la precisión e igualdad en la aplicación de la ley deben primar sobre la claridad en la descripción de la disposición normativa.

La posibilidad de una ICC que, claramente, vaya más allá del sentido literal posible y de la voluntad del legislador, solamente puede admitirse en los casos en que favorezcan al justiciable, quedando, por tanto, proscritas las que perjudiquen al ciudadano.

El TC debe limitar la utilización de la ICC a los casos en que, de acuerdo con las peculiaridades de conflicto social y el bien jurídico protegido, se puede establecer que el legislador penal ha delegado en los tribunales ordinarios la precisión y concreción de una norma penal. Además, esta delegación debe complementarse con una jurisprudencia unificada que garantice, a través de una mayor precisión y concreción del texto normativo, unas mínimas cotas de seguridad jurídica y de igualdad en la aplicación de la ley. 


\section{BIBLIOGRAFÍA CITADA}

Berry, William W. (2014): "Criminal Constitutional Avoidance”, Journal of Criminal Law \& Criminology Vol. 104, no. I: pp. 105-132.

Bunzel, Michael (2007): "La fuerza del principio constitucional de proporcionalidad como límite de la protección de bienes jurídicos en la sociedad de la información” en HEFENDeHL, Roland (ed.), La teoría del bien jurídico ¿Fundamento de legitimación del derecho penal o juego de abalorios dogmático? (Madrid, Marcial Pons) pp. 147-170.

Bustos, Juan y Hormazábal, Hernán (2014): Lecciones de Derecho penal chileno (Santiago de Chile, Librotecnia).

Caballero, Felipe (2006): "Derecho penal sustantivo y efectos en el tiempo de la sentencia del Tribunal Constitucional que declara inconstitucional un precepto legal”, Revista de Derecho (Valdivia), Vol. XIX, no 2: pp. 177-193.

FERnÁNDEZ, José Ángel (2007): “Los delitos de violación y estupro del artículo 365 bis CP: Una racionalización desde el mandato de lex stricta y el principio de lesividad. Especial referencia a la introducción de partes del cuerpo distintas del pene”, Revista Ius et Praxis, vol. II: pp.105-135.

FERnÁNDEZ, José Ángel (2016): "Interpretación conforme a la Constitución: una aproximación conceptual", Revista Ius et Praxis, No 2: pp. 153-188.

Gimbernat, Enrique (2009): Concepto y método de la ciencia en el derecho penal (Madrid, Tecnos).

Kuhlen, Lothar (2012): La interpretación conforme a la Constitución de las leyes penales, (Nuria Pastor, Madrid, Marcial Pons.

López (2004): Decisiones interpretativas en el control de constitucionalidad de la Ley (Valencia, Tirant lo Blanch).

NaVArRo, Irene (2010): El mandato de determinación y tipicidad penal (Madrid, Comares).

FERRERES, Víctor (2002): El principio de taxatividad en materia penal y el valor normativo de la jurisprudencia. Una perspectiva constitucional (Madrid, Civitas).

Romboli, R. (1999): "La aplicación de la Constitución por la jurisdicción ordinaria en Italia”, Cuadernos de Derecho Público „N $\mathrm{N}^{\circ} 7$ : pp.15-40.

RuIz, Fernando (2009): "El delito de tráfico de pequeñas cantidades de droga. Un problema concursal de la ley 20.000", Politica Criminal, vol. 4, n 8: pp. 408-429. Disponible en: http://www.politicacriminal.cl/Vol_04/n_08/Vol4N8A4.pdf [Visitado 13-08-2015].

Ossandón, María Magdalena (2009): La formulación de los tipos penales. Valoración crítica de los instrumentos de técnica legislativa (Santiago de Chile, Editorial Jurídica de Chile).

PÉREZ, Antonio-Enrique (1994): La seguridad jurídica. (Barcelona, Ariel, segunda edición). VAN WeEZEL, Alex (2011): La garantía del principio de tipicidad en la jurisprudencia del Tribunal Constitucional (Santiago de Chile, LegalPublishing).

\section{NORMAS CITADAS}

Decreto Nº100 (17/09/2005), Ministerio Secretaría General de la Presidencia, Texto refundido, coordinado y sistematizado de la Constitución Política de la República de Chile.

Código Penal (12/10/1874). 
LEY N 20.000 (2/02/2005), Sanciona el tráfico ilícito de estupefacientes y sustancias psicotrópicas.

\section{JURISPRUDENCIA CITADA}

Wilhelm Hopp con Ministerio Público (2007): Tribunal Constitucional, requerimiento de inaplicabilidad del Art. 292 CP, 21 de agosto de 2007, Rol $n^{\circ} 739$.

Morrison Cristi con Ministerio Público (2007): Tribunal Constitucional del Art. $4^{\circ}$ de la Ley $\mathrm{N}^{\circ} 20.000$ que sanciona el tráfico ilícito de estupefacientes y sustancias sicotrópicas, 13 de mayo de 2008, Rol $n^{\circ} 293$.

Costa Contreras y otros con Ministerio Público (2010): Tribunal Constitucional, requerimiento de inaplicabilidad del Art, 317 del Código Penal, 17 de junio de 2010, Rol $N^{\circ}$ 1.584 .

Ramírez RuRange con Ministerio PÚblico (2014): Tribunal Constitucional, requerimiento de inaplicabilidad de los Arts. 292 y 293 CP, 23 de diciembre de 2014, Rol n 2651-14.

Meza con Ministerio Público (2005): Corte Suprema, 19 de julio de 2005, recurso de nulidad en contra de la sentencia dictada por el Tribunal del Juicio Oral en lo Penal de Temuco, Rol 2005-05.

Estados Unidos: SKILLING V. UNITED STATES, U.S. 358 (2010).

España: STC 67/1998, de 18 de marzo (Recurso de amparo) y 84/1998, de 20 de abril (Recursos de amparo) relativos al Art. 487 bis del antiguo Código Penal.

España: STC 12/2004, de 24 de febrero (Recurso de amparo) relativo al primer inciso del artículo 563 Código Penal.

España: STC 111/1993, de 25 de marzo (Recurso de amparo) relativo al Art. 321.1 (antiguo) Código penal.

España: STC 69/1989, de 20 de abril (Recurso de amparo) relativo al Art. 207 a) del Reglamento Orgánico de la Policía Gubernativa, de 17 de julio de 1975.

España: STC 53/1994 (Cuestiones de Inconstitucionalidad no 358/1989 y 570/1989, acumulados) Art. 57, párrafo segundo, en relación con el Art. 60 c) de la Ley de Pesca Fluvial de 20 de febrero de 1942.

España: STC 139/1999 de 22 de junio de 1999 (Recurso de amparo), relativo al 174 bis a) $C P$. 
